\title{
NEW NAME FOR A TRIASSIC MAYFLY FROM SOUTH AFRICA (EPHEMEROPTERA)*
}

\author{
By Michael D. HubBaRd ${ }^{1}$ AND E. F. RIEK ${ }^{2}$
}

In a recent paper Riek (1976) described a new species of fossil Ephemeroptera from the Triassic of South Africa as Xenophlebia optata. This mayfly, of which only the wing is known, is sufficiently distinct from other known mayflies to be referrable to a separate superfamily (Xenophlebioidea) without recognizable close phyletic relationship to any other known Ephemeroptera.

Unfortunately, through a chain of circumstances, the fact that Demoulin (1968) had already used the generic name Xenophlebia for a genus of fossil Leptophlebiidae (Ephemeroptera) from the Baltic amber was not taken into consideration. Thus Xenophlebia Riek, 1976, must fall as a junior homonym of Xenophlebia Demoulin, 1968, and be replaced by a new name. The International Code of Zoological Nomenclature also requires that family-group names based on a genus name that is a junior homonym be replaced as invalid. We therefore propose the following new names.

Superfamily Litophlebioidea: new name for Xenophlebioidea Riek, 1976:149.

Family Litophlebiidae: new name for Xenophlebiidae Riek, 1976:150.

Genus Litophlebia: new name for Xenophlebia Riek, 1976: 150.

Entymology: Gr., Litos, meaning frugal, and Phlebos, meaning vein, in reference to the marked reduction in the cubito-anal field of the wing.

Type species: Xenophlebia optata Riek, 1976, by objective synonymy.

Species included: Litophlebia optata (Riek, 1976) new combination.

\footnotetext{
${ }^{1}$ Laboratory of Aquatic Entomology, Florida A\&M University, Tallahassee, Florida 32307, USA.

219 Duffy St., Ainslie, Canberra, ACT 2602, Australia.

*Manuscript received by the editor January 26, 1978.
} 
We thank the Cooperative State Research Service, U.S.D.A., PL 89-106, for partial financial support.

\section{Literature Cited}

Demoulin, G.

1968. Deuxième contribution à la connaissance des Éphéméroptères de l'ambre oligonène de la baltique. Dtsch. Entomol. A., N.F., 15: 233-276.

RIEK, E. F.

1976. An unusual mayfly (Insecta:Ephemeroptera) from the Triassic of South Africa. Palaeontol. Afr. 19: 149-151. 

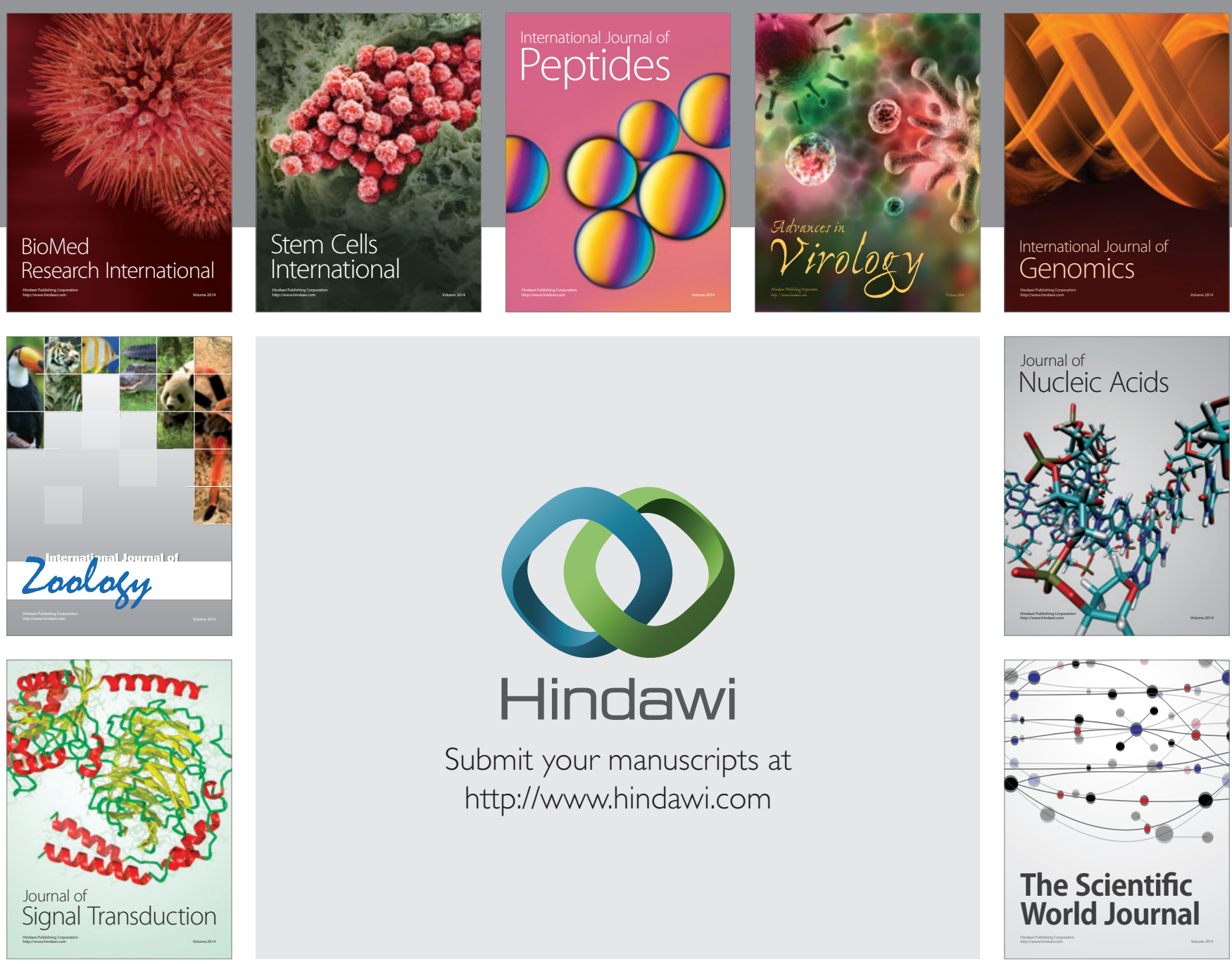

Submit your manuscripts at

http://www.hindawi.com
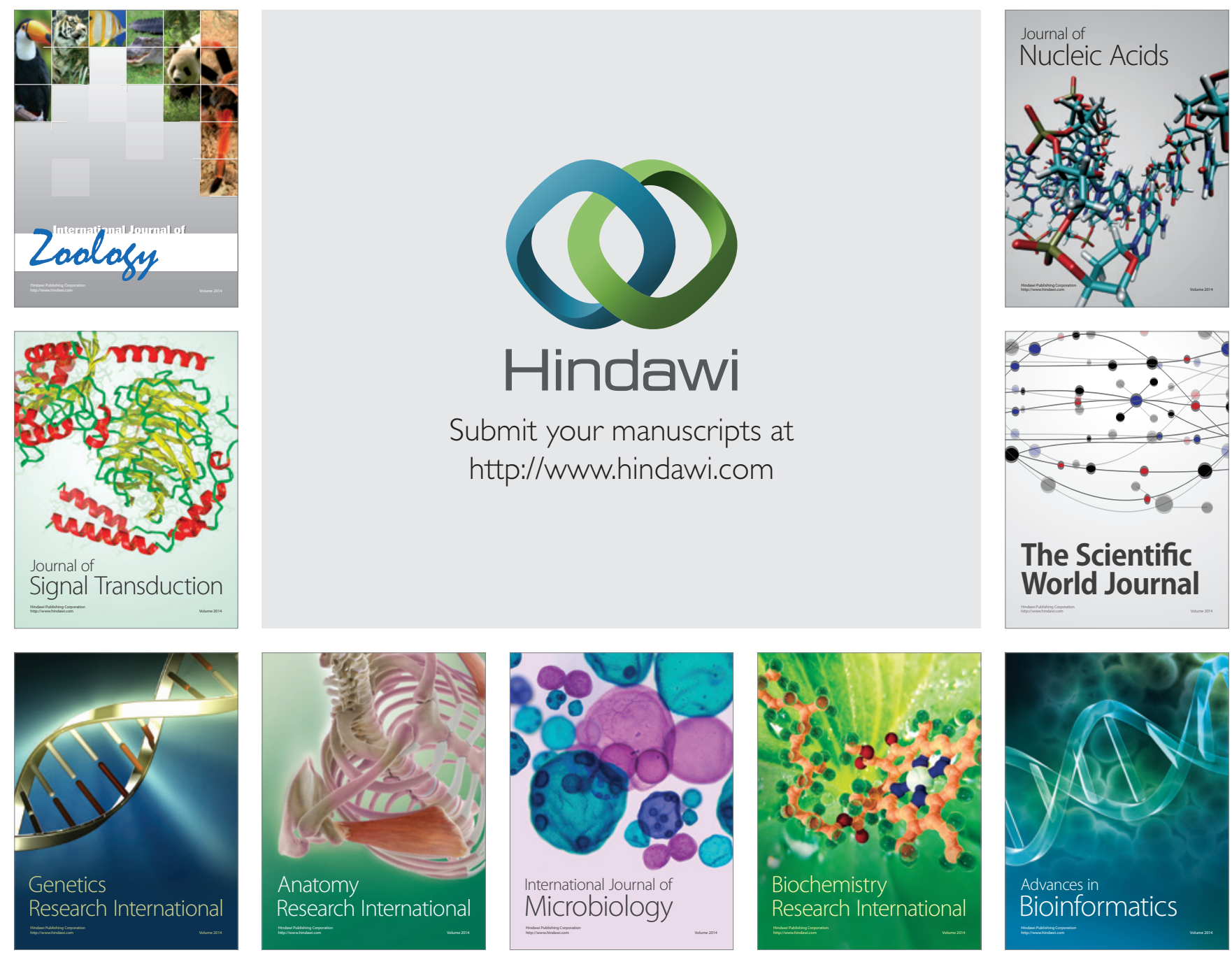

The Scientific World Journal
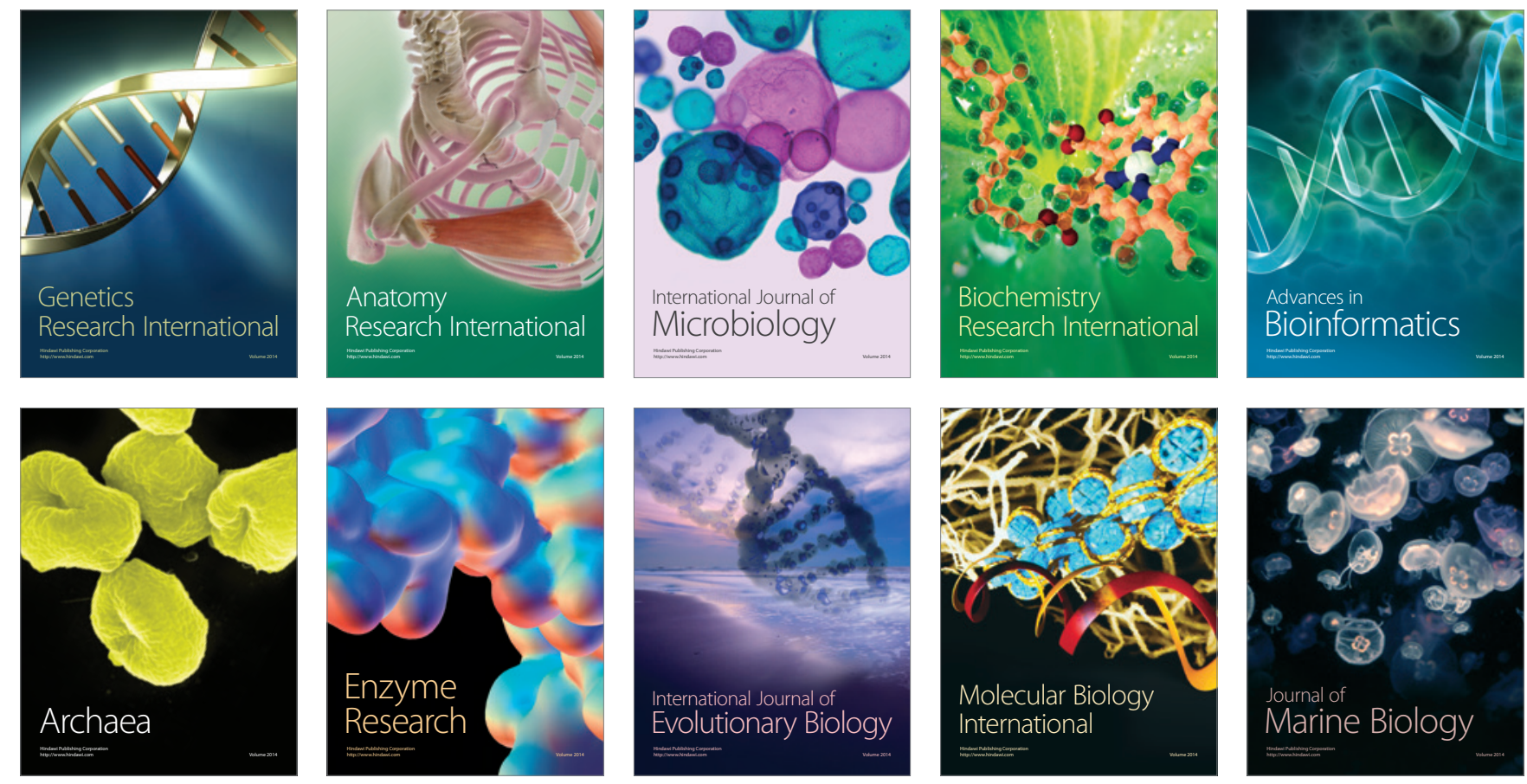